\title{
The November 23, 1980 Irpinia earthquake: an analysis with the new procedure of intensity evaluation
}

\author{
Calvino Gasparini, Valerio De Rubeis, Alessandra Maramai and Maura Murru \\ Istituto Nazionale di Geofisica, Roma, Italy
}

\begin{abstract}
The macroseismic data for the Irpinia earthquake of November 23, 1980, have been re-examined in the light of new procedures of automatic intensity determination created at the ING, with the intention of rendering degree assignation more objective. Beside the advantages offered by the automatic procedures in terms of determined by individual has allowed statistical evaluation of the differences in intensity values, previously incidental or casual components, With the use of an adapted data filter, it was possible to remove all the two methods, giving a more objective representation of the effects.
\end{abstract}

Key words seismology - macroseismic questionnaires - statistics

\section{Introduction}

The disastrous Irpinia earthquake on November 23, $1980(\mathrm{Ms}=6.9)$ was surely one of the strongest events which affected Italy over the centuries, causing the death of about 3000 people, total destruction of 15 towns and the enormous damage to buildings within a radius of approx. $50 \mathrm{~km}$ from the epicenter.

The numerous epicentral locations, indicated by various authors using diverse techniques (see table I), agree, generally, in placing the epicenter on the eastern side of Monte Marzano, in the vicinity of the town of Laviano, which was completely raised to the ground.

In this paper we present a re-examination of the numerous macroseismic data available relating to that earthquake, in the light of automatic procedures of intensity evaluation, which has been in operation at the ING since 1989. From the replies contained in the macroseismic questionnaires, gathered on the oc- casion of the earthquake, new intensity estimates were made using the automatic procedure. The macroseismic field thus obtained was then compared to those previously proposed by Bottari et al. (1982) and by Postpischl et al. (1985) (fig. 1 and 2).

\section{Procedure for the evaluation of macroseismic intensity}

In 1980 the ING had a network of correspondents who collected information regarding earthquake effects on people, things and environment, using macroseismic questionnaires. The network was essentially made of the stations of the «Arma dei Carabinieri» (Police force) spread throughout the country. On the occasion of the November 23, 1980 earthquake, considering the particular gravity of the event, the information on macroseismic effects were obtained both from the questionnaires above mentioned and from a detailed report compiled on site by specialized technicians from the ING.

The questionnaire used in 1980 consisted 


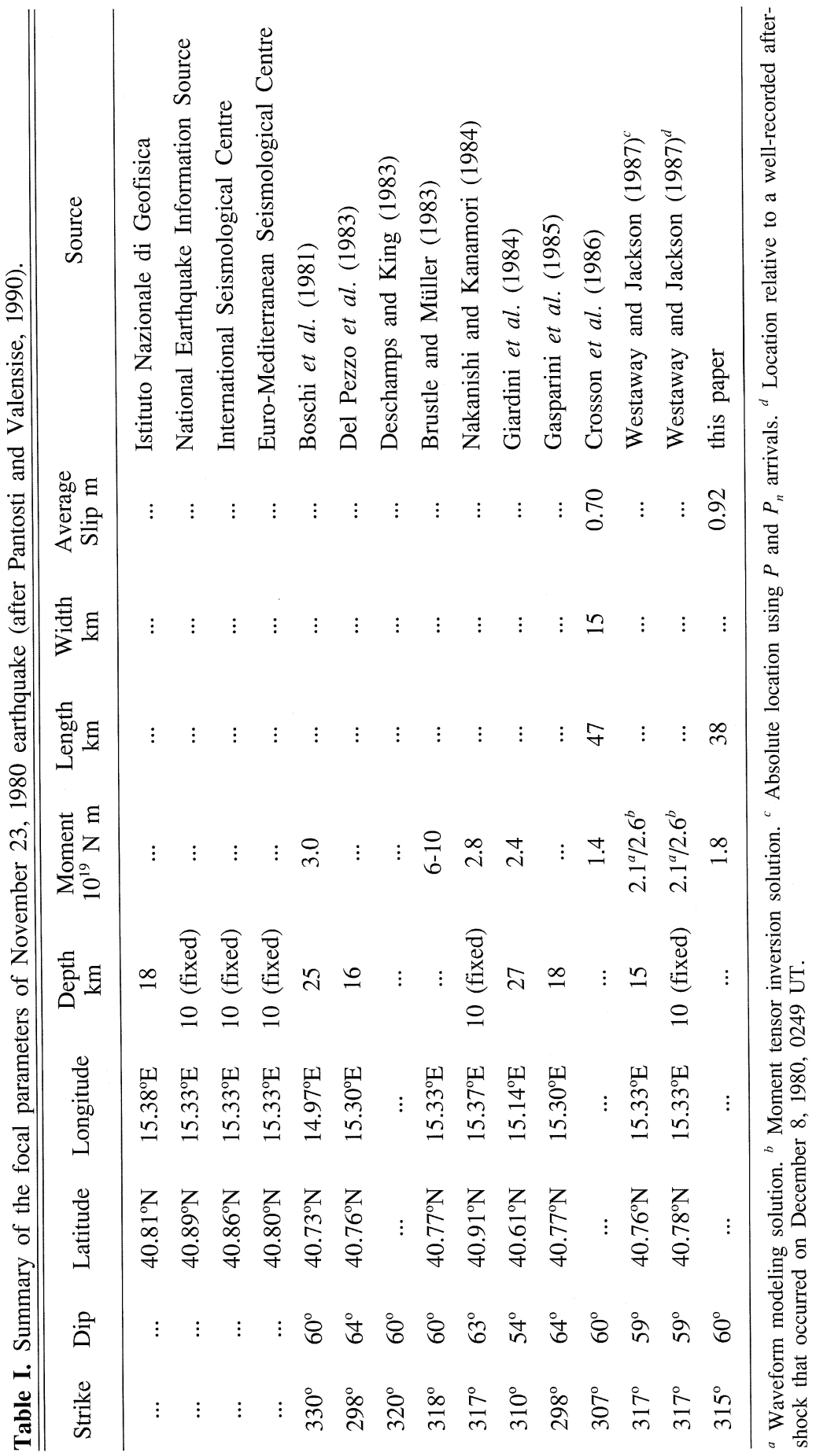




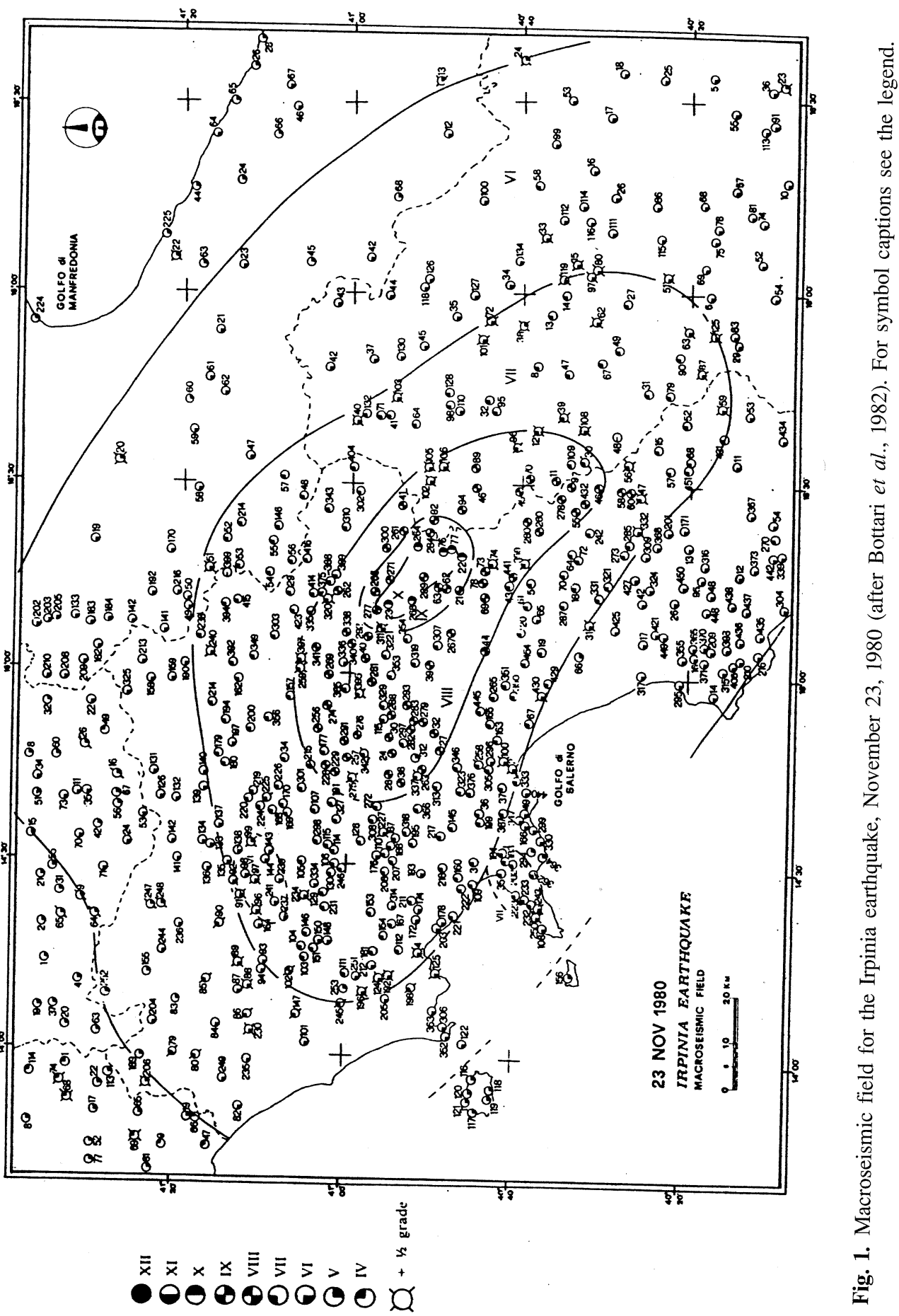




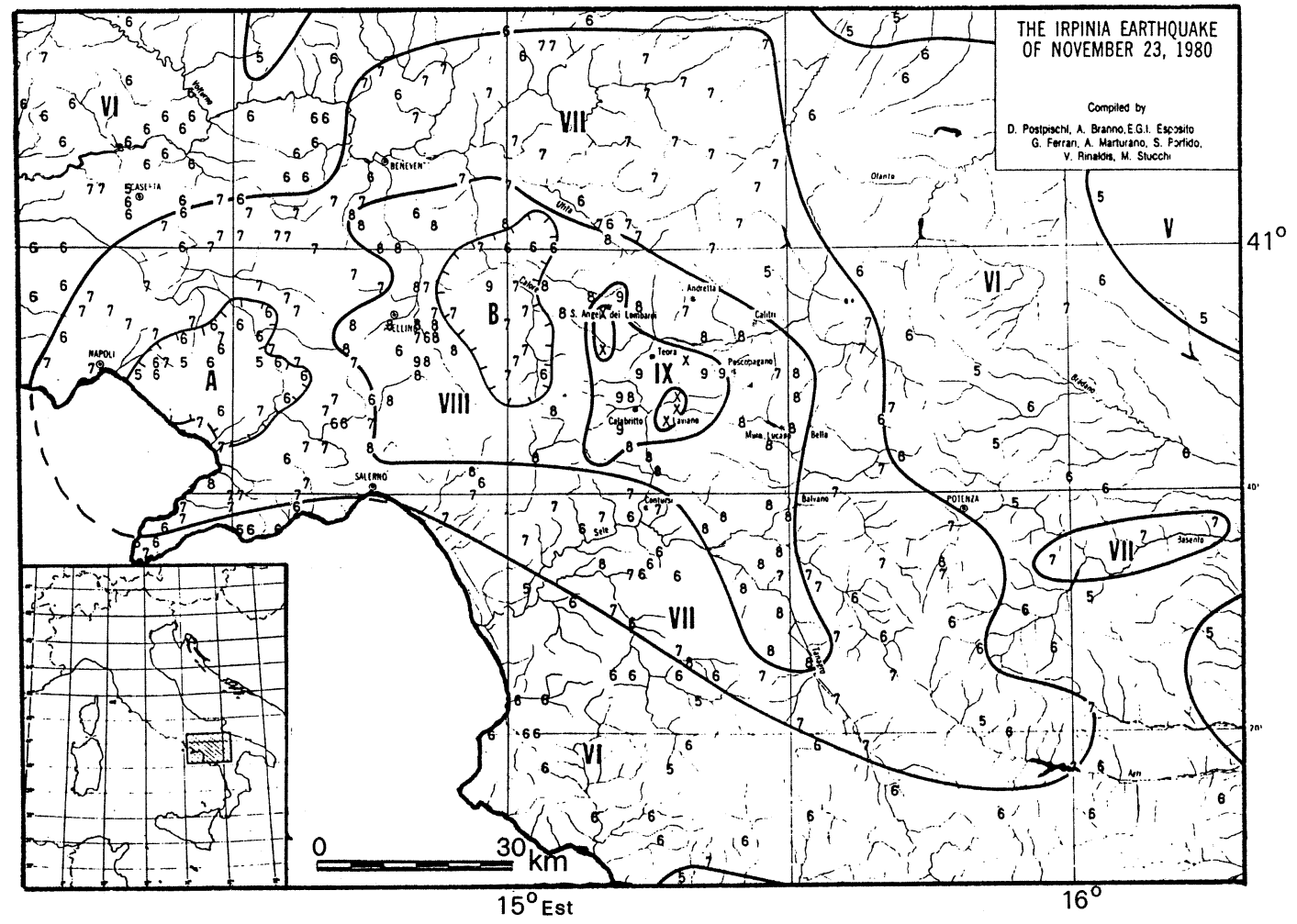

Fig. 2. Macroseismic field for the Irpinia earthquake (after Postpischl et al., 1985).

of 62 questions relative both to the MCS and MSK scales, for the degrees from III to $\mathrm{X}$ (Favali et al., 1980). The omission of definitions relating to the degrees XI and XII is justified by the fact that the valuations of these two degrees are based almost exclusively on the effects produced on the environment. Therefore, those effects were reported separately in the special questionnaires compiled by the ING technicians.

The intensities evaluated from the macroseismic questionnaires show traces of subjectivity, which create difficulties in the interpretation of the phenomenon. With the aim of reducing this, the ING introduced the use of an algorithm (De Rubeis and Gasparini, 1990; Tertulliani et al., 1990a) which was extensive- ly tested, even on cases of historic earthquakes, rendering the evaluation of intensity for individual questionnaires as objective as possible. In the light of these recent developments, it was proposed that the new automatic procedure of evaluation of intensity would be applied to the questionnaires of the Irpinia earthquake of 1980 , using only the replies relative to the MCS scale, which would be more adequate for the typical Italian buildings.

The algorithm used for the assignment of intensity degree for each questionnaire, works through a weighted mean, in which the weights for each degree are reduced as a function of the presence of an affirmative reply relating to the degrees superior to one being examined. The intensity $\bar{I}$, for each question- 
naire, is obtained using an average weight such as

$$
\bar{I}=\frac{\sum_{i=1}^{k} P_{i} I_{i}}{\sum_{i=1}^{k} P_{i}}
$$

where $I_{i}$ is the macroseismic degree relative to the replies with index $i$, index $i=1$ is attributed to the maximum degree, and $P_{i}$ are weights. The latter are calculated in the following way:

$$
P_{i}=\frac{W_{i}}{\sum_{i=1}^{k} W_{i}}
$$

where

$$
W_{i}=\frac{R_{i}}{D_{i}} \prod_{j=1}^{i-1}\left(1-\frac{R_{j}}{D_{j}}\right)
$$

$R_{i}$ is the number of replies given for each degree and $D_{i}$ is the number of questions relative to the degree $i$, present in the questionnaire. The weight $P_{i}$ evaluated in (2.2) is just the probability assigned to a determined degree, that is

$$
\sum_{i=1}^{k} P_{i}=1
$$

The error $\bar{\varepsilon}$ associated with the estimate of $\vec{I}$ is obtained from the equation

$$
\bar{\varepsilon}_{j}=\prod_{i=1}^{k}\left(1-P_{i}\right)
$$

and expresses the probability that the degree estimated is incorrect.

Because of the reason that it is possible to have $n$ macroseismic questionnaires for each location, each one of those with an intensity and an associated error

$$
\bar{I}_{1}, \bar{\varepsilon}_{1} ; \bar{I}_{2}, \bar{\varepsilon}_{2} ; \ldots ; \bar{I}_{n}, \bar{\varepsilon}_{n}
$$

the problem of assignment the intensity degrees to a determined site arises. The evaluation of the final intensity $\bar{I}_{b}$ for each locality is effected through a similar equation to that of (2.1), in which the weights $P_{i}$ are derived from (2.2), keeping in mind that

$$
W_{i}=1-\bar{\varepsilon}_{i}
$$

(Taylor, 1986; Davis, 1986; Vajani, 1974). If one result of the measurement is less precise than another one, its weight is diminished and also its influence. The uncertainty of the estimate of $\bar{I}_{b}$ is given by

$$
\varepsilon_{b}=\left(\prod_{i=1}^{n} \bar{\varepsilon}_{i}\right)^{\frac{1}{n}}
$$

\section{Analysis of macroseismic data from November 23, 1980}

For the realization of this study, replies contained in macroseismic questionnaires, sent out to the correspondents of the Istituto Nazionale di Geofisica after the earthquake of November 23, 1980 were used, as well as those inquiries made on site by ING technicians. This makes together over 600 questionnaires that cover the western and central region of the Italian peninsula, from Umbria to Calabria. Among those, about 450 data for the locations with the intensity greater than $\mathrm{V}$ degree on the MCS scale have been re-examined in this study and the replies contained therein have been treated with the current automatic procedures of intensity evaluation, described above.

The intensity field that results from the reexamination of data is reported in fig. 3 . However, as can be observed and must be emphasized, the tracing of isoseismals was not carried out; even considering the fact that the technique of the isoline stays unreplaceable for the immediate visualization of the effects, it still remains susceptible to subjective interpretation. It was held opportune to report on the map only the distribution of intensities assigned to each location to eliminate other probable sources of subjectivity. In the comparison between intensities obtained and macroseismic fields available in literature (Bottari et al., 1982; Postpischl et al., 1985), it is pos- 


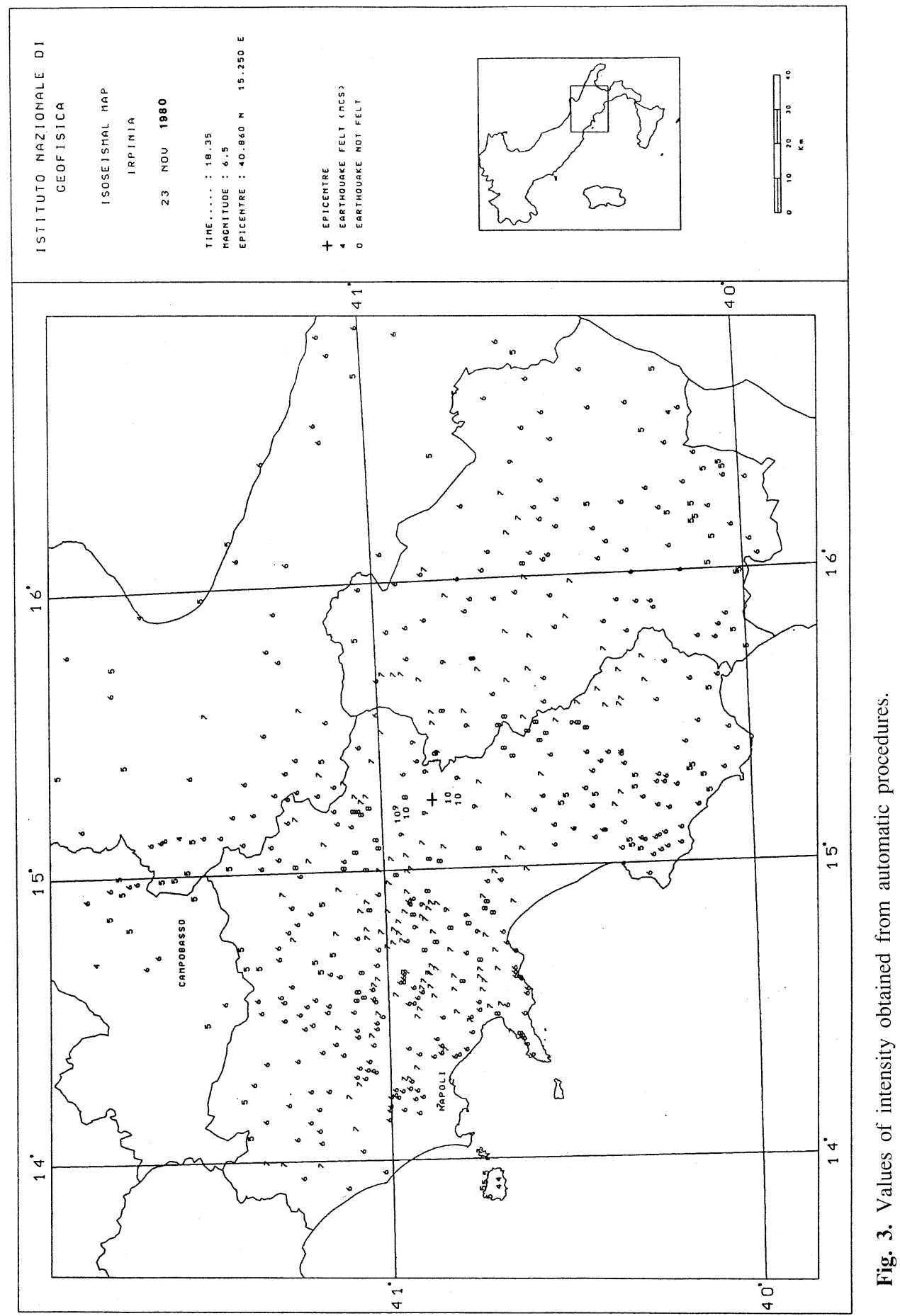


sible to show that the locations with the maximum degree of intensity (X MCS), compared with them corresponding ones in previous studies, generally do not display significant differences between intensity values obtained with the automatic procedure and the procedure used previously.

\section{Filter procedure}

Once the problems on data interpretation have been overcome and macroseismic degrees automatically assigned, it occurs (as in the example in fig. 3) that the intensity values presented are irregularly distributed over the territory. Other uncertainties emerge if all possible errors that influence the regional macroseismic signal are taken in account (those which are accidental and owing to local factors). Among the errors considered for an inhabited center, there are the so-called «local» errors: the interpretation of damage, the different characteristics of the buildings, the effects of site etc. In order to obtain a regular distribution of points from the original data and to represent only the information due to the earthquake (eliminating from the macroseismic data the «local» errors), a filter procedure was introduced. Utilizing the trend analysis, the filter smooths the data, thus giving a representation of the hypothetical regional trend

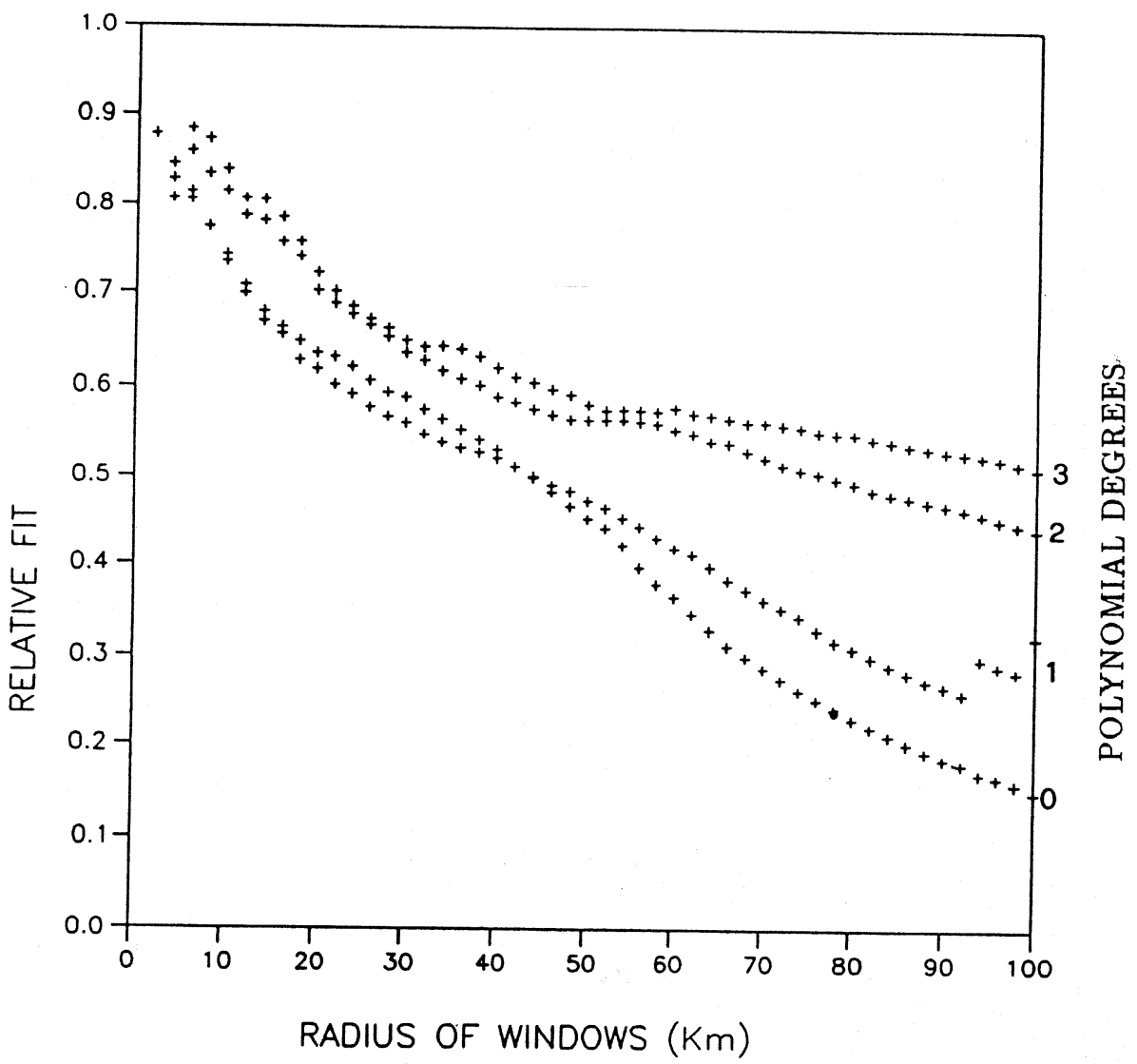

Fig. 4. Filter behaviour (relative fit) versus the radius of circular windows for different trend degrees. 
of the macroseismic field. According to this procedure, already experimented in the macroseismic studies of recent events (Tertulliani et al., 1990a; De Rubeis et al., 1992), the representation of these two components of the macroseismic signal is given in the equation

$$
I_{i}=f\left(x_{i}, y_{i}\right)+\epsilon_{i}
$$

where $x_{i}$ and $y_{i}$ are the geographic coordinates in kilometers of the $i$-th point, $I_{i}$ is the intensity value and $\epsilon_{i}$ is the local contribution. The regional component $f(x, y)$ is estimated as an approximation to the polynomial series of various degrees, according to

$$
f(x, y)=\sum_{r+s=p} a_{r s} x^{r} y^{r}
$$

where $p$ is the polynomial order, $r$ and $s$ are two positive integer numbers that represent all possible combination of exponent of $x$ and $y$ giving the degree less or equal to $p, a_{r y}$ are the coefficients of the equation for every pair of $r$ and $s$; this equation is the base of the trend analysis which has been applied in many areas of Earth science. Generally the distribution of the intensities is estimated with surfaces of gradually increasing degrees of (4.2), choosing the most suitable degree on a statistical basis. The application of a single trend surface to

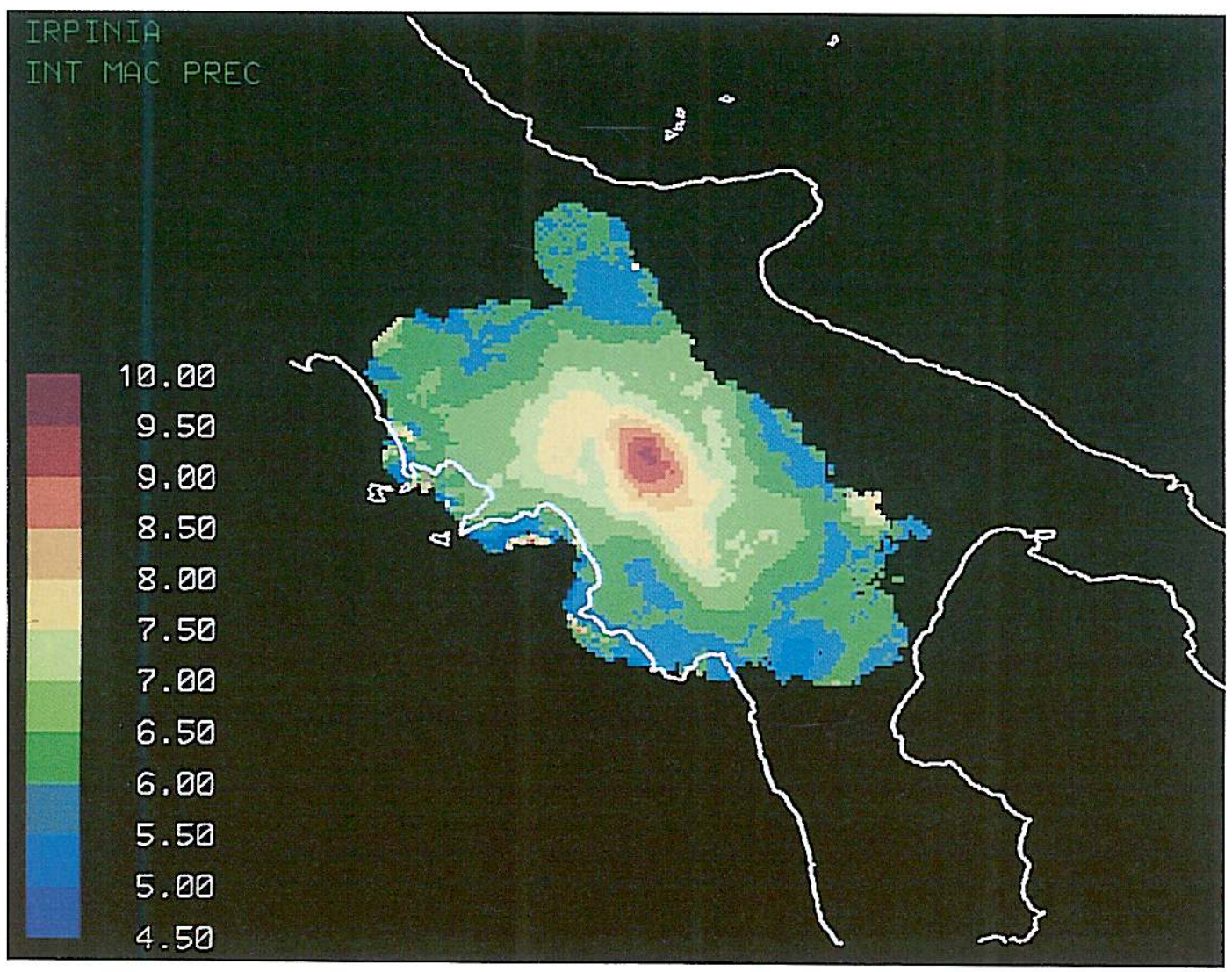

Fig. 5. Filtered values of macroseismic intensities for the original data. 
the entire macroseismic field did not appear advantageous, in the first stage it used elevated degree surfaces $(>5)$ in order to obtain values of fit barely sufficient. The technique used is therefore based on the repeated use of many trend surfaces of a given degree, large enough to include a sufficient number of data and to permit overlap with adjacent points on the grid: in this way each original datum participates in more trend surfaces.

With the reduction of the area on which each single trend analysis is conducted, fewer data points are used, in favour of a greater simplicity of calculation. Once the coefficients of the various trends are calculated, only the central points of the surfaces considered are used for estimation, so reducing the consequences of border effects. Another characteristic of the filter is its great flexibility: in fact, varying the degree of the surfaces and the range of influence, the effect of the filter itself can be dosed. Ranges of little value and large surface degrees give similar estimations to those of the original data, obtaining a little filtered definitive result; however, extending the ranges so that each point of the grid contains all original data, and at the same time adopting zero degree (giving, simply, the average value of the original point), a flat level is obtained equal to the average of all the macroseismic intensities: the filter effect is then at its greatest. As criterium for the choice of the

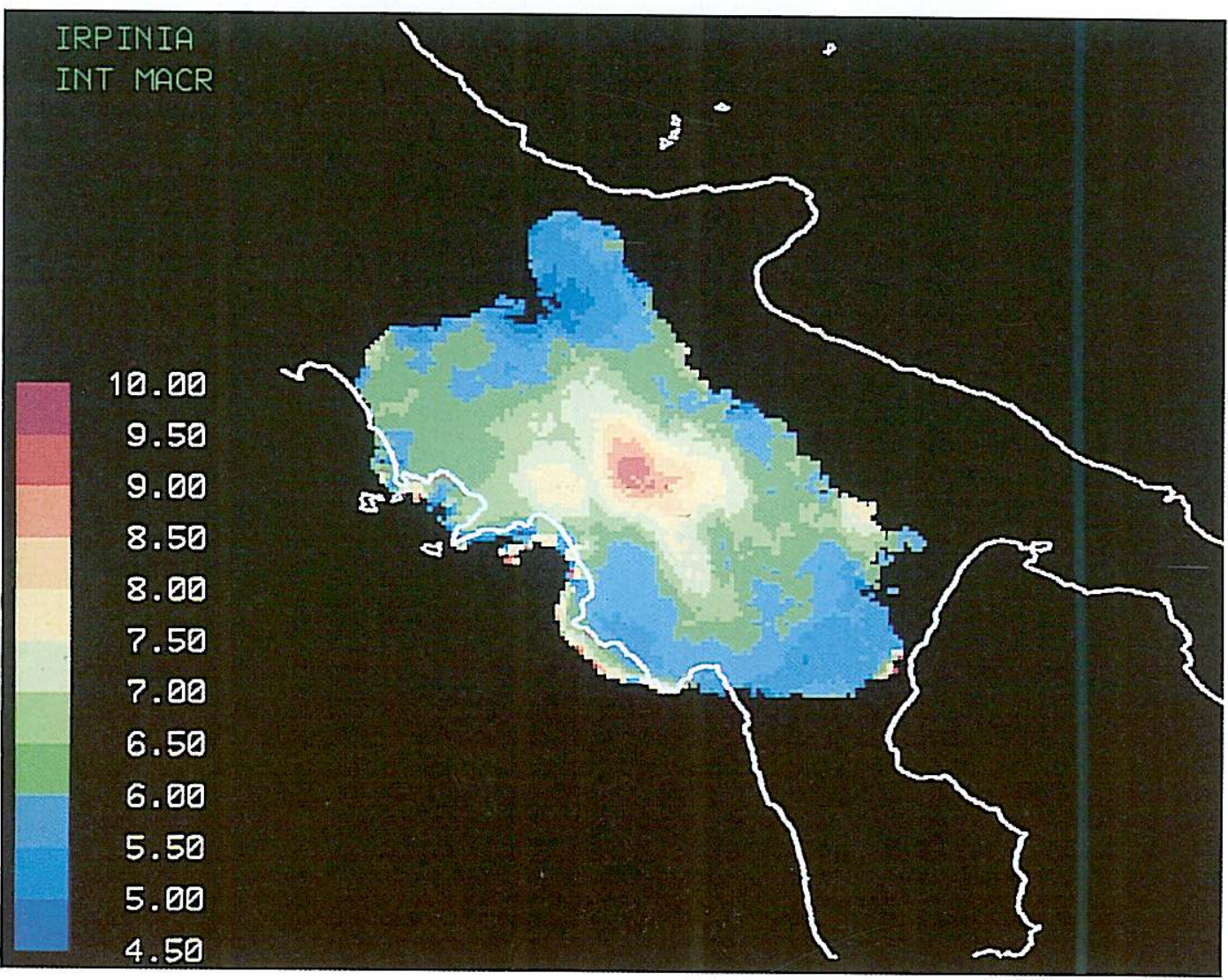

Fig. 6. Filtered values of macroseismic intensities derived by automatic procedures. 
parameters, a relative goodness of fit was defined

$$
F_{r}=1-\frac{\sum_{i=1}^{n}\left(\hat{Z}_{i}-Z_{i}\right)^{2}}{\sum_{i=1}^{n}\left(Z_{i}-\bar{Z}\right)^{2}}
$$

where $\hat{Z}_{i}$ are the calculated values, $Z_{i}$ are the original values, while $\bar{Z}$ is the average of all the $n$ data. In this preliminary phase the analyses are not centered on the junctions of the grid, but only on the original data. The denominator expresses the maximum filter action equivalent to zero degree with a range large enough to permit each center to include all the original values. Plotting the values of $F$ for each polynomial degree and for various ranges, a similar pattern to that of fig. 4 can be noted: after a sharp fall of fit, it can be noted that the slope of every curve (expecially those relative to 2 nd and 3 rd order) tends to be more horizontal with the increasing of the radius of windows; this can be interpreted as a relative greater resistance of the original data to the large radius filter respect to small radius values filter. It can be held that, the resistance is owing to the presence of the regional component (regional macroseismic signal). The degree of the surface and the range of influence are chosen in order to safeguard the

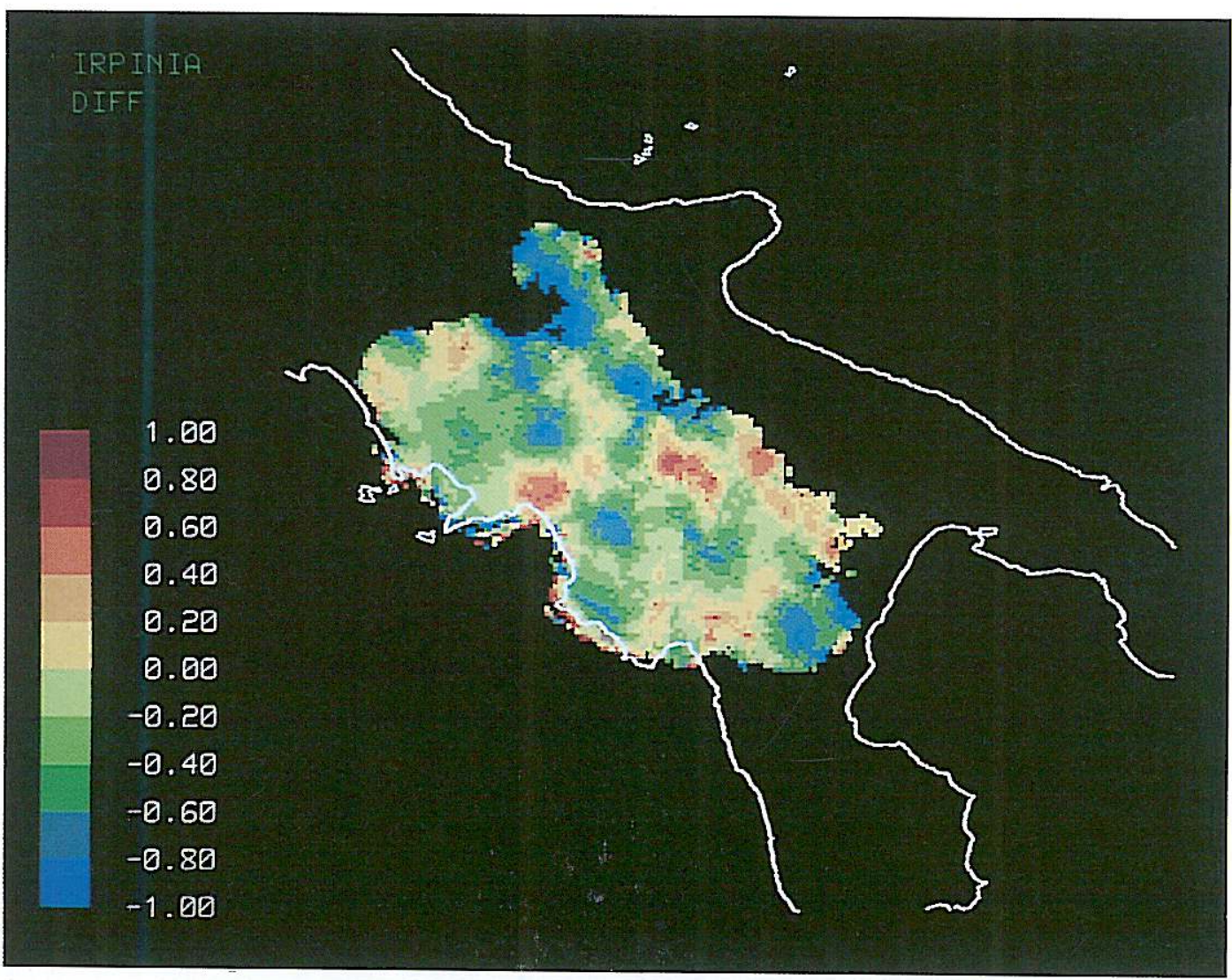

Fig. 7. Residuals map obtained subtracting the original intensity values (traditional procedure) from the data got by means of automatic procedures. 
regional component, eliminating the local one that, for its characteristic, is sensitive to a filter acting with small radius values. Where the density of original data is too low for the calculation of a partial surface, it is not carried out, leaving that portion of space empty. Operating this way, the tracing of the isoseismal is substituted with the definition of a filtered field, significant only in the zones of sufficient data density, and with values relative only to the regional component of the macroseismic field. On the basis of results obtained (shown in fig. 4), filter parameters equivalent to a second polynomial degree and a $20 \mathrm{~km}$ range were adopted for the earthquake of November 23, 1980.

Figures 5 and 6 show the filtered values of the intensity attributed by the ING operators with traditional methods for the earthquake of 1980 and those obtained in the course of the present study through the automatic procedures above described respectively. For both fields the same filter was used in order to compare only the regional components of the fields. From the comparison of the two figures it can be observed that in the data set obtained with the automatic procedure (fig. 6) there is a notable diminution of the areas of VI and VII degrees (represented in green) in favour of the area of $\mathrm{V}$ (blue). The difference between the two fields shown in fig. 7 (residuals), was obtained by subtracting the intensity values calculated in 1980 from those determined using the new procedure.

In this figure, the colours correspond to various differences in intensity. Negative residuals, that are zones coloured green and blue, indicate areas in which the intensities are less in respect to the corresponding intensities calculated in 1980. Positive residuals are indicated by various colours from yellow to red. A prevalence of blue and green areas is notable, which indicates the general tendency towards diminution of intensity degree. It may also be seen that the presence of positive anomalies localized in the zone around the epicenter underlines another difference between the two interpretations; in fact, the pattern of the traditionally obtained data (fig. 5) shows a less accentuated anisotropy in respect to the one of the automatically produced data (fig. 6). The latter presents an obviously lobate structure.

\section{Conclusions}

From the interpretation of figs. 5 and 6 it can be affirmed that the intensity values obtained by automatic procedure show, in general, a good agreement with the estimates made by the experts (traditional procedure), allowing a greater objectivity in the assignation of intensity and in semplifying the operation. In addition it should be noted that differences in the intensity field still remain; they are geographically well localized and not attributable to casual factors or correlated to errors of intensity valuation. Finally, it can be seen that the distribution of errors is not dependent on the distance from the epicenter and does not follow either the trend of the macroseismic field, nor that of the differences. It is possible, to state that an estimation of the macroseismic field can be obtained with the automatic procedure of intensity evaluation and with the use of filter techniques. This procedure, presents a good correspondence with the traditional system, and it allows the demonstration of patterns of macroseismic phenomena that can help better understanding the correlations with geophysical and geographical parameters.

\section{REFERENCES}

Bottari, A., L. Giovani, E. Lo Giudice, V. Longo, M.C. SpadeA and M. VecCHI (1982): Regional macroseismic field of the 1980 Irpinia earthquake, Annali di Geofisica, 25, 27-84.

DAVIS, J.C. (1986): Statistics and data analysis in geology, (John Wiley and Sons, New York), 2nd edition, $1-646$.

De Rubeis, V. and C. Gasparini (1990): Confronto di algoritmi per il calcolo dell'intensità sismica in Atti del $9^{\circ}$ Convegno Nazionale, GNGTS (CNR, Roma), 17-23.

De Rubeis, V., C. Gasparini and P. Tosi (1992): Determination of the macroseismic field by means of trend and multivariate analysis of questionnaire data, BSSA, 82 (3), 1206-1222.

Favali, P., L. Giovani, M.C. Spadea and M. Vecchi (1980): Il terremoto della Valnerina del 19 Settembre 1979. Indagine Macrosismica, Annali di Geofisica, 33, 79-89. 
Pantosti, D. and G. Valensise (1990): Faulting mechanism and complexity of the November 23, 1980, Campania-Lucania earthquake, inferred from surface observations, J. Geophys. Res., 95 (B10), 319-341.

Postpischl, D., A. Branno, E.G.I. Esposito, G. FerraRi, A. Marturano, S. Porfido, V. Rinaldis and M. STUCCHI (1985): The Irpinia earthquake of November 23, 1980, CNR - PFG Atlas of isoseismal maps of Italian earthquakes, 114 (2A).

TAYLOR, J.R. (1986): Introduzione all'analisi degli errori (Zanichelli, Bologna), 1-223.

Tertulliani, A., V. De Rubeis, A. Maramai, P. HoAng Trong and G. Herquel (1990): French-Ital- ian border earthquakes, 2nd $A B$ Workshop on macroseismic methods, Ljubljana.

Tertulliani, A., C. Gasparini, M. Murru and F. RiGUZZI (1990): The 20 February 1743 earthquake: a historical re-examination, in Proceedings of the third International Symposium on Historical Earthquakes in Europe, Liblice, 252-256.

Vajani, L. (1974): Statistica descrittiva (Etas Libri, Milano), 1-567.

(received November 27, 1992; accepted February 15, 1993) 